\title{
Els universals lingüístics i el marcatge en l'ensenyament de la pronunciació del català com a llengua estrangera
}

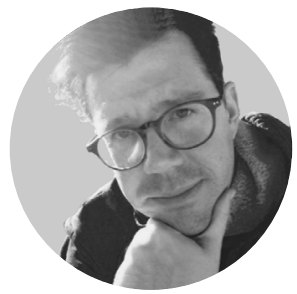

FRANCESC TORRES-TAMARIT

CNRS-UNIVERSITÉ PARIS 8

francescjosep.torres@gmail.com

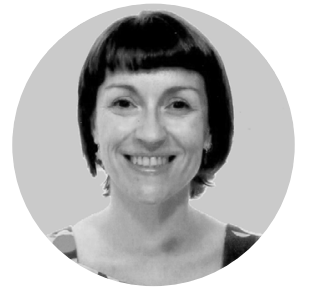

MARIA DEL MAR VANRELL

UNIVERSITAT DE LES ILLES BALEARS

mm.vanrell@uib.cat
A quest article explora la contribució que poden fer els universals lingüístics i la noció del marcatge tipològic a l'ensenyament i aprenentatge del sistema vocàlic i l'entonació del català. L'anàlisi demostra que el català se situa en un nivell mitjà de complexitat tipològica en relació amb les llengües més parlades dels nouvinguts. Les àrees de dificultat tindran a veure amb el contrast entre les vocals mitjanes obertes i tancades, la producció de la vocal neutra, la presència lleugerament majoritària d'accents tonals de tipus alt o ascendent i d'interrogatives absolutes amb entonació descendent. Aquests resultats poden tenir implicacions importants per a l'ensenyament i l'aprenentatge de la pronúncia del català com a llengua estrangera. La primera té a veure amb l'ordre natural d'adquisició de determinades estructures i pot aplicar-se al disseny de programacions o materials didàctics. La segona es relaciona amb la direcció de la generalització en l'aprenentatge de les estructures en què existeix una relació d'implicació i s'aplica a la facilitació del procés d'adquisició de la llengua. Finalment, es destaca la necessitat de recollir evidències que permetin abonar o falsar les hipòtesis formulades des de l'enfocament basat en el marcatge tipològic.

PARAULES CLAU:

universals lingüístics; marcatge tipològic; català; vocalisme; entonació; intervenció didàctica

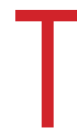
his paper explores how language universals and typological markedness can contribute to the process of teaching and learning the vowel system and the intonational phonology of Catalan as a second language. When compared to the languages with which Catalan is in contact, we conclude that its relative typological markedness is moderate. We further identify areas of difficulty for learners: the contrast between open- and close-mid vowels, the production of schwa, and the slight majority presence of high or rising pitch accents and of yesno questions with falling intonation. These results can have important implications for teaching and learning Catalan pronunciation. The first implication can be applied to the design of curricula, and hinges upon the order of acquisition of structures: the least marked structure should be first introduced. The second implication has to do with the direction of linguistic generalizations during acquisition, and can be applied to the explicit teaching of structures in which there is an implicational relationship between them. Finally, we highlight the need to gather evidence to either support or falsify the hypotheses formulated from the typological markedness approach to second language acquisition defended in this paper.

\section{KEYWORDS:}

language universals; typological markedness; Catalan; vocalism; intonation; didactic Intervention 


\section{Introducció}

\subsection{La interllengua}

E n general es parteix de la suposició entre els investigadors sobre l'adquisició d'una segona llengua (L2 d'ara endavant) que el fet d'adquirir-la implica l'establiment d'una gramàtica que permetrà a l'aprenent d'aproximar-se a la llengua meta o LM al nivell tant de la producció com de la comprensió (Barrios, 2018). Aquesta gramàtica que el parlant construeix a partir de determinats trets de la seva llengua de partida (L1), però també a partir de la generalització d'altres trets de la LM, s'anomena interllengua (Selinker, 1972). Des d'aquesta perspectiva l'aprenent imposarà una determinada estructura en les dades lingüístiques disponibles i construirà un sistema internalitzat. Així doncs, l'objectiu principal dels investigadors que treballen en aquesta àrea és descriure i explicar el patró que segueixen els aprenents de llengües després d'haver adquirit la seva llengua inicial mitjançant la caracterització del sistema de la interllengua.

L'estudi de la fonologia de la interllengua cerca explicar el coneixement que té l'aprenent sobre el sistema de sons de la LM, el qual no necessàriament ha de coincidir amb el de la L1 ni amb el de la LM (Barrios, 2018). Fins ara, els investigadors sobre la fonologia de la interllengua han centrat la seva recerca en diversos factors que poden influenciar la construcció de la gramàtica de la interllengua: l'input de la LM o d'aprenentatge (en aquest sentit cal destacar el corpus d'evidència creixent a favor que l'input escrit influencia també les hipòtesis dels aprenents sobre el sistema fonològic de la LM, veg. Escudero et al. 2008, Showalter i Hayes-Harb 2013, Zhou i Hamann 2020, entre d'altres), la influència de la L1, el marcatge tipològic (que té a veure amb les característiques que són més comunes en les llengües del món ${ }^{1}$ ), i l'edat i l'ús que es fa de la L1 i LM (veg. Barrios, 2018 per a una revisió).

\subsection{L'estudi de la fonologia de la interllengua dels aprenents de català}

L'adquisició de la fonologia del català com a segona llengua o com a llengua estrangera és una disciplina en desenvolupament que compta amb un cos descriptiu prou ampli de treballs que segueixen sobretot un enfocament contrastiu (Carrera-Sabaté i Prieto, 2012-2019, la Col·lecció “Llengua, immigració i ensenyament del català", Gràcia Solé, 2004, 2005; Julià, 2014; Roseano, 2019; Wang, 2019, 2020), tot i que també trobem estudis que se centren en l'anàlisi de la percepció dels sons de la LM per part dels aprenents (Cebrian 2019, Mora i Nadeu 2012), estudis que se centren en enfocaments tipològics $\mathrm{i}$ aporten arguments que provenen de la patologia $\mathrm{i}$ de l'adquisició del llenguatge (Llach, 2010; Cicres i Llach en procés de revisió) i d'altres que segueixen una aproximació multiteòrica (Cutillas, 2014). A continuació resumirem els treballs citats en les línies precedents amb l'objectiu de presentar un estat de la qüestió i alhora fer una anàlisi que permeti conèixer quina ha estat l'evolució de l'àrea.

Com ja s'ha esmentat, l'enfocament contrastiu és indiscutiblement el més aplicat en els treballs sobre l'adquisició del català com a segona llengua. Aquest tipus d'anàlisi es basa en la presentació de les característiques fonològiques (el sistema vocàlic $\mathrm{i}$ consonàntic, l'estructura sil·làbica, el sistema accentual i l'inventari entonatiu) de la L1 i del català com a LM amb l'assumpció que les similituds i les diferències entre la L1 i la LM seran necessàries i suficients per explicar les àrees de facilitat i de dificultat dels aprenents de català. Dit d'una altra manera, les dificultats emergeixen quan no existeix un equivalent en la L1 d'un determinat fenomen o estructura de la LM. Amb aquesta perspectiva, doncs, es comparen el sistema vocàlic i consonàntic, l'estructura sil·làbica $i$ els patrons accentuals del català amb els del berber, fula, panjabi, romanès, soninké, tagal, ucraïnès, i xinès a la Col·lecció "Llengua, immigració i ensenyament del català"; amb els de l'anglès, el castellà, el francès, el rus i el xinès mandarí a Julià (2014), i amb el xinès a Wang $(2019,2020)$ pel que fa només a qüestions sobre el sistema consonàntic. En aquest sentit, els treballs de Gràcia Solé $(2004,2005)$ són una mica diferents ja que no tenen la intenció de detectar àrees de dificultat sinó d'analitzar la diversitat tipològica de les llengües que conviuen a Catalunya a partir de les característiques del català. Carrera-Sabaté i Prieto (2012-2019) i Roseano (2019) tenen en comú que incorporen l'entonació a l'hora d'il·lustrar les similituds i les diferències entre el català, d'una banda, i el castellà i l'anglès, de l'altra (Carrera-Sabaté i Prieto, 2012-2019), i entre el català i l'italià (Roseano, 2019).

Treballs com el de Cebrian (2019) o Mora i Nadeu (2012), en canvi, parteixen de models (Best i Tyler, 2007; Flege, 1995; Kuhl i Iverson, 1995) que atribueixen la influència de la L1 en la interllengua al fet que els aprenents percebin els sons de la LM a través de les categories de la L1. La diferència fonamental entre l'enfocament contrastiu basat en la Hipòtesi de l'anàlisi contrastiva de Lado (1957) i el de Flege (1995), per exemple, és que mentre que la Hipòtesi de 
l'anàlisi contrastiva de Lado (1957) prediu que els sons més semblants s'adquiriran abans, segons Flege (1995), com que els sons més semblants s'identificaran amb els sons de la L1, aquest fet podrà dificultar-ne la creació de noves categories (veg. Cebrian, 2019). A partir d'aquest marc, Cebrian (2019) identifica el grau de semblança entre una sèrie de vocals $i$ diftongs del català i de l'anglès. Concretament, troba que el so vocàlic [æ] anglès és identificat de manera semblant a la [a] catalana, que els sons corresponents a la $[\varepsilon]$ en anglès $i$ català són molt propers i que la $[\mathrm{e}]$ catalana és més propera $\mathrm{a}$ la $[\mathrm{I}]$ anglesa que a la $[\varepsilon]$. El fet que les vocals $[\mathrm{e}, \varepsilon]$ catalanes s'identifiquin amb vocals laxes en anglès ${ }^{2}$, i que les vocals laxes en anglès no puguin ocupar la posició de nucli d'una síl·laba oberta, farà que paraules com bé i be tendeixin a pronunciar-se amb un diftong, «bei», per part dels anglòfons. Una manera de practicar aquestes vocals, doncs, seria partir d'exemples que il·lustrin aquesta diferència, com ara serè, seré i rei. D'altra banda, les vocals mitjanes posteriors s'assimilen a la vocal oberta posterior arrodonida (curta) [p] Segons Cebrian (2019), la [o] catalana es podria treballar a partir d'una producció curta de la vocal anglesa llarga [॰:] i parells mínims que il·lustrin la diferència entre vocals laxes i diftongs del tipus cantó i tou o bo i bou. Mora i Nadeu (2012), al seu torn, investiguen l'efecte de l'ús del castellà com a L2 en l'habilitat dels bilingües català-castellà de percebre i produir el contrast entre les vocals mitjanes obertes i tancades /e/ i / $/ \varepsilon /$ del català. Els participants a l'experiment de percepció eren parlants bilingües català-castellà amb el català com a llengua inicial però amb un percentatge diferent en l'exposició i l'ús d'aquesta llengua. La capacitat de percebre el contrast es va avaluar mitjançant una tasca de discriminació del tipus $\mathrm{AXB}^{3}$ amb un continu /e/-/E/ en deu passos. Pel que fa a la producció es varen obtenir mostres de la vocal mitjana oberta $/ \varepsilon /$ en cognats (maleta [molćtə] vs. [maléta]) i no cognats (galleda [gəКćðə] vs. cubo [kúßo]) en català. El resultats demostraren que el participants que usaven el castellà amb més freqüència discriminaren les vocals /e/ i / / / amb menys precisió i més lentitud i, a més, varen tenir una producció més semblant a la del castellà a l'hora de produir la vocal / $\varepsilon$ /, sobretot en els cognats (maleta [məlétə] vs. [maléta]). Segons els autors aquests resultats indiquen que en un context de contacte lingüístic, el grau d'experiència amb la L2 afecta les categories vocàliques de la L1.

Els treballs de Llach (2010) i Cicres i Llach (en procés de revisió) parteixen d'un enfocament tipològic. Consideren que el fet de poder predir les àrees de dificultat va més enllà de determinar les estructures que o bé no són presents en la L1 o no ho són en la LM. Per exemple, Llach (2010) ordena els segments vocàlics $\mathrm{i}$ consonàntics del català segons el grau de dificultat que presenten tenint en compte tant la percepció com la producció i traça un itinerari ideal per ensenyar-los en un context multilingüe com el de Catalunya. A Cicres i Llach (en procés de revisió) es revisen diferents models teòrics basats en la idea de transferència o en les dificultats que poden presentar determinades estructura de la fonologia de la LM. A partir d'aquestes teories, doncs, els autors se centren en tres aspectes de la fonologia del català: les vocals i les consonants, l'estructura sil-làbica, l'accent i alguns processos fonològics característics del català com ara la sonorització d'obstruents a final de mot quan van seguides d'un segment vocàlic.

El treball de Cutillas (2014), en què s'analitza l'adquisició del sistema consonàntic del català per part de parlants amb l'àrab i el xinès com a L1 segueix un enfocament multiteòric. Cutillas (2014), a partir de les dades recollides mitjançant una tasca d'obtenció de mots a partir d'imatges, troba evidència que avala diferents models teòrics com el Model de la transferència, el de la Hipòtesi de l'anàlisi contrastiva (Lado, 1957), el Model interllengua (Selinker, 1972) i la Hipòtesi del marcatge diferencial (Eckman, 1977, 1985). No entrarem aquí a precisar el tipus d'evidència presentada per l'autora, sinó que remetrem el lector a aquest treball i, concretament, a les pàgines 49-52, en què l'autora comenta els resultats a partir dels diferents marcs teòrics.

\subsection{Objectius}

L'objectiu principal d'aquest treball és explorar la contribució que poden fer els universals lingüístics i la noció del marcatge tipològic a l'ensenyament i aprenentatge dels següents aspectes fonològics del català: el sistema vocàlic $i$ el to i l'entonació. ${ }^{4}$ Amb aquest objectiu, doncs, presentarem les diferències que es deriven d'un enfocament contrastiu i d'un enfocament basat en el marcatge tipològic (apartat 2), situarem el vocalisme del català així com el seu sistema entonatiu en relació amb les llengües dels nouvinguts més parlades a Catalunya i a les Illes Balears (apartat 3), farem algunes consideracions sobre el tipus d'intervencions didàctiques que es poden fer a partir de la idea del marcatge tipològic (apartat 4) i, finalment, clourem l'article amb unes conclusions (apartat 5). Les llengües més parlades que conviuen amb el català a Catalunya i les Illes Balears són les següents: llengües del grup romànic (castellà, francès, gallec,

\section{${ }^{66}$ L'objectiu principal d'aquest treball és explorar la contribució que poden fer els universals lingüístics i la noció del marcatge tipològic a l'ensenyament i aprenentatge dels següents aspectes fonològics del català: el sistema vocàlic $i$ el to $i$ l'entonació.'}


italià, portuguès, romanès), del grup germànic (alemany, anglès, neerlandès, suec), del grup eslau (búlgar, eslovac, polonès, rus, ucraïnès), del grup indoirànic (panjabi), llengües afroasiàtiques (l'amazic o semítiques com l'àrab), nigerocongoleses (kwa com l'igbo o mandé com el bambara), sinotibetanes (xinès), austronèsiques (tagal) i ameríndies (andines com el quítxua o equatorials com el guaraní). No pretenem fer una comparació sistemàtica del català amb totes aquestes llengües, sinó il·lustrar determinats trets del sistema vocàlic o entonatiu del català a partir d'aquestes llengües.

\section{L'enfocament contrastiu versus l'enfocament basat en el marcatge tipològic}

E ls enfocaments contrastiu i el basat en el marcatge tipològic es defineixen en dues hipòtesis concretes que són la Hipòtesi de l'anàlisi contrastiva (HAC d'ara endavant), proposada per Lado (1957), i la Hipòtesi del marcatge diferencial (HMD) (Eckman, 1977). Alguns anys més tard, Eckman (1991) va plantejar una altra hipòtesi (la Hipòtesi de la concordança estructural, HCE), que recorre també a la noció del marcatge tipològic i pretén superar l'anterior en alguns aspectes que es consideraran a continuació.

Tant la HAC com la HMD tenen com a objectiu determinar les àrees de dificultat que tindrà un aprenent d'una L2 amb qualsevol LM. La HAC aborda aquesta qüestió a partir de les diferències entre la L1 i la LM, de manera que es prediu que hi haurà dificultats quan hi hagi diferències entre la L1 i la LM i absència de dificultats en cas de similituds entre les dues llengües. L'evidència que aquesta hipòtesi no es pot mantenir ha provingut d'estudis en què es demostra l'existència de dificultats per adquirir un determinat tret, tot i haver-hi similituds entre la L1 i la LM (Richards, 1971; d'Anglejan i Tucker, 1975; apud Eckman, 1985) i, per contra, casos en què les diferències entre les dues llengües no provoquen cap dificultat (Gradman, 1971; apud Eckman 1985). Com a alternativa, es proposa la HMD, la qual defensa que, tot i que les diferències entre la L1 i la LM són necessàries per poder explicar la dificultat en l'adquisició d'un determinat tret, no són suficients per a una explicació adequada. Així doncs, a més de les diferències entre les dues llengües, també és necessari poder mesurar el grau de dificultat que permeti predir les diferències que provoquin problemes. Segons la HMD, el nivell de dificultat es pot predir a partir de la noció del marcatge tipològic (veg. (1)):

(1) Un determinat fenomen o una estructura $X$ és relativament més marcat en una llengua en comparació amb un altre fenomen o estructura Y si en les llengües del món la presència d'X en una llengua implica la presència $d^{\prime} Y$, però la presència d'Y no implica la presència $d^{\prime} X$ (la traducció és nostra).
A partir d'aquesta definició, Eckman (1977) formula la HMD com s'il·lustra a (2).

(2) Les àrees de dificultat que tindrà un aprenent d'una segona llengua es poden predir a partir de la comparació entre la L1 i la LM de manera que:

a. Les àrees de la LM que siguin diferents de la L1 i siguin relativament més marcades que en la L1 seran difícils.

b. El grau de dificultat associat amb els aspectes de la LM que són diferents i més marcats que en la L1 correspon al grau relatiu de marcatge associat amb aquests aspectes.

c. Les àrees de la LM que són diferents de les de la L1, però no són relativament més marcades que en la L1, no seran difícils.

Eckman $(1977,1985,1991)$ presenta evidència convincent a favor d'aquesta hipòtesi. N'és un bon exemple el contrast de sonoritat d'obstruents en posició de coda síl·làbica. Segons Dinnsen i Eckman (1978), qualsevol llengua que presenti un contrast de sonoritat en posició de coda el presenta també en posició d'obertura sil·làbica, però no viceversa. També qualsevol llengua que tingui un contrast de sonoritat en posició d'obertura medial necessàriament el tindrà també en obertura inicial, però no al contrari. Aquest exemple de direccionalitat de la dificultat es documenta a Moulton (1962), en què es demostra que la diferència entre l'alemany i l'anglès pel que fa al contrast de sonoritat en posició de coda sil-làbica causa més dificultat per als parlants d'alemany com a L1 que aprenen l'anglès que per als parlants d'anglès com a L1 aprenents d'alemany. L'explicació és que l'anglès té un contrast de sonoritat d'obstruents en posició d'obertura inicial, medial i també en posició de coda final, mentre que l'alemany manifesta aquest contrast només en posició d'obertura inicial i medial. En alemany, en posició de coda sil-làbica, ja sigui medial o final, en canvi, aquest contrast es neutralitza a favor de les obstruents sordes.

Com s'ha indicat, Eckman (1991) planteja una hipòtesi complementària a la HMD, també a partir de la noció del marcatge tipològic, com veiem a (3).

(3) La Hipòtesi de la concordança estructural, HCE (Eckman, 1991: 24). Les generalitzacions universals vàlides per a l'adquisició de les primeres llengües ho són també per a la de les interllengües.

La motivació de la HCE és poder donar compte dels patrons que apareixen en la interllengua, que no són ni patrons de la L1 ni de la LM, però que, tot i així, obeeixen els patrons que es troben en les llengües del món. Com que el patró no apareix en una àrea de diferència entre la L1 i la LM, ja que no pertany a cap de les dues, no pot explicar-se a partir de la HMD. En resum, la HCE aborda les limitacions de la HMD fent prediccions sobre la natura de la gramàtica 
de la interllengua, d'una banda, i expandint el domini de la hipòtesi més enllà de les àrees de diferència entre la L1 i la LM.

\section{Aspectes concrets de la pronunciació del català}

\subsection{Les vocals}

E n aquesta secció volem repassar molt breument un conjunt de teories que tenen com a objectiu explicar la tipologia de l'inventari de sons de les llengües naturals a partir de la classificació que es fa a Gordon (2016: 57-71). Referim el lector a aquestes pàgines per a més referències bibliogràfiques. En aquesta secció només ens fixarem en les teories sobre els inventaris vocàlics. Després, situarem l'inventari vocàlic del català en relació amb algunes de les llengües més parlades a Catalunya i a les Illes Balears des d'un punt de vista tipològic tenint en compte les nocions d'universal lingüístic i de marcatge, sovint fent referència a les teories esmentades.

A. La teoria de la dispersió. Segons aquesta teoria, la forma que adopten els inventaris fonològics està guiada per un principi de maximització dels contrastos en el pla perceptiu. Pel que fa a les vocals, això explicaria per què entre els sistemes de cinc vocals proliferen inventaris del tipus /i, e, a, $\mathrm{o}, \mathrm{u} / \mathrm{i}$ no pas del tipus, /i, I, e, $\varepsilon$, ə/, per exemple, el qual faria un ús més restringit de l'espai vocàlic a l'hora d'establir els contrastos fonològics.

B. La teoria de la dispersió i la focalització. Aquesta teoria també parteix de la idea que els inventaris que consisteixen en vocals perceptivament més disperses són els més afavorits tipològicament. Ara bé, aquesta proposta proposa una revisió de la teoria de la dispersió i hi incorpora dos components. El primer és la noció de focalització, segons la qual s'afavoreixen les tres vocals perifèriques pel fet de tenir formants més pròxims entre si: el primer $\mathrm{i}$ el segon en el cas de /u, a/, i el tercer $\mathrm{i}$ el quart en el cas de /i/. L'avantatge que suposa tenir formants pròxims entre si també explica la preferència tipològica per les vocals anteriors arrodonides (/y, ø/), que tenen el segon i el tercer formants més pròxims entre si, en contraposició a les vocals posteriors no arrodonides (/u, $\gamma /$ ). El segon component que incorpora aquesta teoria és el pes més rellevant que dona als valors del primer formant vocàlic, que és el correlat acústic de l'alçada, en contraposició als dels segon, tercer i quart formants, que són menys rellevants. És per això que tipològicament l'espai vocàlic acostuma a fraccionar-se verticalment i no horitzontalment. És a dir, s'afavoreixen els contrastos d'alçada i no de posterioritat.

Aquesta teoria, la qual només incorpora aspectes relacionats amb la percepció, mostra dificultats a l'hora d'explicar, per exemple, la preponderància de la vocal neutra en els inventaris vocàlics de les llengües del món. És per això que sovint s'ha parlat sobre la necessitat d'incorporar en les teories tipològiques sobre els inventaris vocàlics la noció de facilitat articulatòria. La preferència per la vocal neutra es podria explicar recorrent a aquesta noció, ja que la seva presència sembla no interactuar amb la distribució en l'espai vocàlic de les vocals no centrals. Una altra crítica a les teories que només se centren en la dimensió perceptiva ve motivada per l'existència dels sistemes vocàlics verticals, aquells que només fan ús de la dimensió de l'alçada, és a dir, sistemes amb només dues o tres vocals centrals. Una crítica més general a aquestes teories té a veure amb la dificultat que tenen a l'hora d'explicar comportaments asimètrics entre les dimensions anterior i posterior, o el fet que, i això és rellevant per a l'aprenentatge de les segones llengües, llengües amb sistemes fonològics equivalents poden mostrar graus de variació fonètica considerables entre les mateixes categories contrastives.

C. Economia de trets. Segons aquesta teoria, la noció de simetria és rellevant a l'hora de determinar la forma dels inventaris de sons contrastius de les llengües. De manera molt generalitzada, els inventaris amb cinc vocals incorporen dues vocals anteriors i dues de posteriors. De manera similar, els inventaris amb set vocals incorporen, a més, una segona vocal mitjana tant en la regió anterior com en la posterior. La idea central de l'economia de trets és que s'afavoreixen aquells inventaris que maximitzen l'ús del nombre més mínim de trets fonològics a l'hora d'expandir el seu inventari. Clements (2009) va proposar un índex per avaluar el grau d'economia de trets que presenta un sistema, el qual es calcula dividint el número de segments de l'inventari pel número de trets fonològics que es necessiten per caracteritzar-ne el conjunt de contrastos.

El sistema vocàlic tònic del català consta de set vocals orals curtes, és a dir, sense distinció pel que fa a la nasalitat o la llargada: /i, e, $\varepsilon, a, o, o, u /$. En posició àtona, i a causa d'un procés fonològic de reducció vocàlica, el sistema es redueix a tres vocals en català oriental: $[i, u$, o]. Segons la base de dades de l'UPSID (Maddieson 1992), que inclou informació sobre 451 llengües, un percentatge prou considerable (27 llengües de 67) de les llengües amb set elements vocàlics inclouen /i, e, $\varepsilon, \mathrm{a}, \mathrm{o}, \mathrm{\jmath}, \mathrm{u} /$. Per tant, podem concloure que la distribució de vocals contrastives del català és tipològicament poc marcada. Ara bé, l'UPSID recull més llengües amb sis o cinc vocals, 84 i 130 llengües, respectivament, que llengües amb set vocals, les quals arriben a 67 en aquesta base de dades.

De les llengües romàniques que es parlen a Catalunya $\mathrm{i}$ a les Illes Balears, el gallec, el portuguès i l'italià també comparteixen el mateix sistema vocàlic tònic que caracteritza el català. Ara bé, cap d'aquests sistemes incorpora la vocal neutra [ə]. Només el portuguès europeu té dues vocals centrals no baixes, la vocal quasioberta central [e] (que es pot sentir en alguns parlars barcelonins) i la vocal tancada central [i]. Els aprenents lusòfons de català podrien, aleshores, experimentar dificultats a l'hora d'articular una sola vocal central [ə], que ocuparia acústicament un lloc intermedi entre $[\mathrm{e}] \mathrm{i}[\mathrm{i}]$. 
El català de les Illes Balears planteja un problema addicional quant al sistema vocàlic. Un dels trets més característics de la major part dels parlars baleàrics és la presència de la vocal neutra en posició tònica: $p[\partial] \mathrm{ra}, \mathrm{cr}[\partial] \mathrm{ure}$, enc[j]s. Aquesta vocal es correspon a la e oberta del català central i a la e tancada del català occidental. Ara bé, no tots els parlars del dialecte balear presenten vocal neutra tònica. A la banda de ponent d'Eivissa, el sistema vocàlic tònic és com el del català central, és a dir, de set vocals i sense vocal neutra tònica (els pobles de Sant Josep, Sant Agustí, Sant Antoni i Santa Agnès). A Mallorca, el mateix passa a Alaró, Binissalem i Lloseta, i a Menorca, a Maó, Alaior i es Mercadal (Villangómez, 1978: 206-207). Formentera és l'única illa de l'arxipèlag balear en què no coexisteix cap altre sistema vocàlic que el de vuit vocals tòniques contrastives. Des del punt de vista tipològic, la vocal neutra és una vocal afavorida en contextos de reducció vocàlica. Ara bé, la seva presència en els inventaris vocàlics com a element contrastiu és marcada. De fet, la teoria fonològica sovint assumeix l'existència d'una restricció universal (però violable) en contra de la vocal neutra en posició tònica. En definitiva, l'aprenentatge d'un sistema balear amb vuit vocals contrastives afegeix una dificultat afegida, en la mesura en què s'introdueix un nou element en el sistema. Ara bé, assumim que l'ensenyament de la vocal neutra en posició tònica a partir de parells mínims com ara set (el número, amb e oberta) i set (necessitat de beure, amb neutra tònica) o deu (el número, amb e oberta) i deu (forma del verb deure, amb vocal neutra tònica) facilitarà l'aprenentatge dels casos en què el resultat de l'aplicació de la reducció vocàlica produeix una vocal neutra. És a dir, que l'aprenentatge d'un segment en un context tipològicament marcat, en aquest cas la vocal neutra en posició tònica, pot facilitar-ne l'adquisició en els contextos tipològicament no marcats, en posició àtona. Pensem, també, que l'adquisició del sistema vocàlic tradicional de vuit vocals de la majoria de parlars balears pot veure's afectat per processos de canvi lingüístic que semblen afectar algunes subvarietats del balear. Veny (1977) ja va notar la "confusió" entre la o oberta i la o tancada en eivissenc, i a Torres (1983) ja es pot llegir que "certament té tota la raó en Joan Veny quan diu que hi ha vacil lacions quant al timbre de les $\mathrm{O}$, però també hem observat un fenomen que es dóna a uns determinats indrets podem dir que sistemàticament: la no distinció del timbre obert $\mathrm{i}$ tancat de les dues $\mathrm{O}$ entre la població més jove de la ciutat d'Eivissa i del poble de Santa Eulària. Aquests parlants no diferencien ni acústicament ni fonèticament un mot amb vocal $\mathrm{O}$ oberta d'un mot $\mathrm{amb}$ vocal O tancada. Aquesta no distinció implica la confusió dels mots, dels parells mínims següents: dóna/dona, ós/ os, mòlt/molt, són/son, sòl/sol, còs/cos, dónes/dones, fóral fora, etc. I encara tampoc fan la $\mathrm{O}$ oberta d'una sèrie de paraules que per raons de fonètica històrica tocaria fer-les obertes: por, col, respon, dol, etc. se pronuncien tancades." (Torres 1983: 23). A l'eivissenc urbà contemporani també s'ha observat recentment un altre fenomen de pèrdua de contrast entre vocals en posició tònica. Hamann i TorresTamarit (2018) han demostrat l'existència, entre parlants jóvens de la ciutat d'Eivissa, d'un sistema vocàlic tònic de tan sols sis vocals on no només no hi ha distinció entre la o oberta i la o tancada, sinó que la distinció entre la e oberta i la vocal neutra en posició tònica es neutralitza a favor de la vocal neutra tònica. Les causes d'aquest canvi lingüístic que s'observa en el sistema vocàlic tònic de l'eivissenc urbà contemporani podrien ser diverses. Una possible causa interna podria relacionar-se amb la freqüència, ja que la presència de la e oberta en el lèxic és menor que la de la vocal neutra. D'altra banda, les causes també podrien relacionar-se amb qüestions de caire sociolingüístic. Ara bé, ja podem avançar que l'aprenentatge de la distinció entre vocals mitjanes obertes i tancades, així com de la distinció entre la e oberta i la vocal neutra tònica, en el context eivissenc, pot presentar moltes dificultats afegides, sobretot si tenim en compte que el sistema fonològic dels parlants nadius ja no es correspon al que s'acostuma a descriure per al balear en els treballs tradicionals de dialectologia catalana. Pel que fa al mallorquí, les nostres observacions de caràcter purament impressionístic també apunten al fet que la vocal neutra tònica acostuma a substituir, en alguns casos, les vocals mitjanes anteriors oberta i tancada. Ara bé, a diferència de l'eivissenc, sembla ser que aquest tipus de substitucions només s'observen en parlants que tenen el català com a L2. Calen, en definitiva, estudis descriptius més aprofundits sobre els sistemes fonològics de totes les subvarietats contemporànies del dialecte balear.

El castellà i el romanès són les úniques llengües romàniques d'aquest grup que presenten un sistema vocàlic més reduït, sense vocals mitjanes obertes. L'aprenentatge de les vocals mitjanes obertes per part dels parlants que tenen el castellà o el romanès com a llengua inicial és ben conegut, i s'explicaria per la marcadesa universal de les vocals mitjanes obertes en relació amb les vocals mitjanes tancades. El francès i el portuguès, a més de vocals mitjanes obertes, també incorporen vocals nasals, les quals són absents en català ${ }^{5}$. El francès, a més, incorpora tres vocals anteriors arrodonides (/y, ø, œ/). Com que la presència en un sistema fonològic de vocals nasals o vocals anteriors arrodonides, més marcades, implica universalment la presència de vocals orals i vocals anteriors no arrodonides, l'adquisició de les vocals orals o les vocals anteriors no suposa cap problema per als aprenents de català que tenen el francès o el portuguès com a llengües inicials. El sistema vocàlic del francès, però, quan el comparem amb el del català, és rellevant en relació amb una altra qüestió. És ben conegut el fet que fonemes equivalents en dues llengües poden ocupar espais acústics diferents. Les vocals altes i mitjanes en francès, per exemple, són més altes que les vocals corresponents en català. L'aprenent, en aquests casos, no ha d'adquirir cap categoria fonemàtica nova, però sí que ha d'incorporar coneixement relatiu a la implementació fonètica de les categories fonològiques, coneixement que no és pas universal, sinó particular per a cada llengua.

Abans ens hem referit breument a la dificultat dels aprenents de català $\mathrm{amb}$ el castellà com a llengua inicial a l'hora d'adquirir la distinció entre vocals mitjanes obertes $(/ \varepsilon, \mathrm{o} /)$ i tancades $(/ \mathrm{e}, \mathrm{o} /)$. Pel que fa a aquesta qüestió és interessant destacar que la majoria de llengües eslaves que es parlen a Catalunya i a les Illes Balears tampoc incorporen aquest contrast, però que, a diferència del castellà o del rus, 
només incorporen en el seu sistema vocàlic vocals mitjanes obertes $(/ \varepsilon, \mathrm{\jmath} /)$. Aquesta és la situació en búlgar, en eslovac, en polonès i en ucraïnès. Si partim de la generalització que les vocals mitjanes obertes són més marcades que les vocals mitjanes tancades, la teoria del marcatge tipològic prediria que l'aprenentatge del contrast entre unes i altres es produiria més ràpidament en els parlants d'aquest grup de llengües eslaves que en els parlants de castellà o rus. Ara bé, en relació amb aquest punt cal tenir en compte que sovint suposades distincions fonemàtiques basades en transcripcions no han pogut ser sempre caracteritzades acústicament. Aquest és el cas en els dos sistemes vocàlics de quatre vocals tipològicament més comuns: /i, e, a, o/ i /i, e, a, u/. Becker-Kristal (2010) ha demostrat que la suposada diferència entre $/ 0 / \mathrm{i} / \mathrm{u} /$ en llengües diferents no existeix, i que la realització d'aquest so vocàlic posterior tendeix a ocupar un espai acústic intermedi en relació amb els sons canònics /o/ i / / /. Ens hauríem de demanar si aquest és el cas per a les vocals mitjanes tancades del castellà i el rus, d'una banda, i per a les vocals mitjanes obertes de les llengües eslaves esmentades anteriorment, d'altra banda. L'espai acústic que ocupen aquestes vocals mitjanes en aquestes llengües determinarà en gran mesura el grau de dificultat pel que fa a l'aprenentatge del contrast entre vocals mitjanes obertes i tancades.

Entre les llengües que més es parlen a Catalunya i a les Illes Balears, concretament en aquelles que són més allunyades tipològicament, la situació pel que fa als sistemes vocàlics no difereix gaire de la descrita anteriorment per a les llengües romàniques i les eslaves. Pel que fa al panjabi (grup indoirànic) i al bambara (grup nigerocongolès), trobem el mateix sistema de set vocals descrit per al català, amb absència de la vocal neutra, però. Podríem agrupar la resta de llengües en dos grups: les que incorporen entre tres i quatre vocals en el seu sistema, i les que n'incorporen cinc. La majoria de varietats amazigues i l'àrab clàssic es caracteritzen per un sistema tipològicament molt poc marcat, constituït per les tres vocals perifèriques menys marcades tipològicament: /a, i, u/. Ara bé, cal tenir en compte que la vocal neutra té una presència quasifonemàtica en amazic, ja que en la majoria de casos la seva distribució es pot predir a partir de l'estructura sil·làbica. Pel que fa a l'àrab, que és una llengua coneguda per molts parlants d'amazic, la situació no és tan senzilla. Tot $i$ que l'àrab clàssic, utilitzat en els registres formals, tan sols consta de les vocals /i, u, a/, molts dialectes àrabs incorporen dues vocals mitjanes tancades, /e/ i /o/. A més, tant /e/ com /o/ es poden realitzar amb els al·lòfons $[\varepsilon]$ i $[0]$, respectivament, la distribució dels quals es pot predir a partir del context fonètic. El quítxua (grup amerindi) és també una llengua amb tan sols tres vocals: /i, u, a/. Ara bé, aquestes tres vocals es poden realitzar com $\mathrm{a}[\mathrm{a}, \varepsilon, o]$, respectivament, en presència d'una consonant uvular adjacent. Pel que fa a les llengües amb cinc vocals, trobem el guaraní (grup amerindi), amb l'inventari següent: /i, e, a, o, u/. Com en algunes varietats de l'àrab, però, les vocals mitjanes tancades també poden realitzar-se com a vocals mitjanes obertes en determinats contextos fonètics. El guaraní no presenta vocal neutra, però sí una vocal alta central [i]. La situació del guaraní és similar a la de l'igbo (grup nigerocongolès). Tot i això, en igbo les tres vocals més perifèriques de les cinc vocals /i, e, a, o, u/, és a dir, /i, u, $\mathrm{a} /$, alternen amb les seves respectives variants amb el tret [-arrel avançada] a causa d'un procés d'harmonia vocàlica. Les vocals amb el tret [-arrel avançada] es pronuncien amb l'arrel de la llengua retreta. Finalment, cal tenir en compte que molts parlants d'aquestes llengües en coneixen d'altres d'origen europeu, com ara el francès o el castellà.

Com hem vist en aquesta secció, el sistema vocàlic del català se situa en un nivell mitjà de complexitat tipològica en relació amb les llengües més parlades amb què conviu. Les dificultats associades a la seva adquisició sovint es relacionaran amb el contrast que s'estableix entre les vocals mitjanes obertes i tancades, la producció de la vocal neutra, i la implementació fonètica particular de les seves categories fonològiques.

\subsection{El to i l'entonació}

El català, ben igual que la majoria de les llengües europees, és una llengua entonativa. Les llengües entonatives es diferencien de les llengües tonals com el bambara, l'igbo $\mathrm{o}$ el xinès perquè les diferències que es manifesten a través de les variacions tonals no impliquen distincions lèxiques o morfològiques. Les funcions de l'entonació són múltiples: distingir diferents tipus d'enunciats (declaratives, interrogatives, vocatius, etc.), marcar els canvis de torn en els intercanvis comunicatius, segmentar l'enunciat en unitats més petites $i$, per tant, més fàcils de processar, transmetre actituds proposicionals i emocions, etc. S'ha de tenir en compte que en les llengües tonals el to coexisteix i interactua amb l'entonació. Per tant, és errat pensar que les llengües tonals no tenen entonació. Tradicionalment s'ha fet una distinció entre les llengües amb accent lèxic (stress languages) $\mathrm{i}$ les llengües tonals (tone languages) a partir d'una sèrie de propietats a partir de les quals les llengües s'han ubicat en un o altre grup. La realitat, però, és força més complexa $i$ se sap que hi ha llengües que tenen característiques dels dos grups. Aquestes llengües híbrides s'han anomenat llengües amb accent tonal. El suec, per exemple, és una llengua que pertany a aquest grup. Pel que sabem, aquests grups de llengües no estan distribuïts uniformement en el món. Per exemple, les llengües tonals tendeixen a concentrar-se a Àfrica, a Amèrica central i al sud-est d'Àsia, però, en canvi, són pràcticament inexistents a Euràsia, al nord d'Amèrica $\mathrm{i}$ a Austràlia. Sembla que la majoria de llengües del món són tonals tot i que aquesta prevalença disminueix en bases de dades equilibrades pel que fa a la filiació genètica (segons la base de dades de Maddieson 2013, les llengües tonals representarien el 41,8\% i en la del WALS, el 29,9\%).

La gramàtica entonativa del català està formada per 7 accents tonals, és a dir, tons que s'associen amb les síl·labes tòniques, i 7 tons de frontera, és a dir, tons que delimiten les unitats tonals. En general trobem una situació d'equilibri entre els accents alts i els descendents tant pel que fa als accents tonals 
$\left(\mathrm{H}^{*}, \mathrm{~L}+\mathrm{H}^{*}, \mathrm{~L}+{ }_{\mathrm{iH}} \mathrm{H}^{*}, \mathrm{~L}+<\mathrm{H}^{*} \mathrm{i} \mathrm{L}^{*}+\mathrm{H}\right.$, de tipus ascendent, versus $\mathrm{L}^{*}, \mathrm{H}+\mathrm{L}^{*}, \mathrm{H}^{*}+\mathrm{L} \mathrm{i} i \mathrm{H}+\mathrm{L}^{*}$, de tipus descendent) com als tons de frontera $(\mathrm{H} \%, ! \mathrm{H} \%, \mathrm{~L} ! \mathrm{H} \%, \mathrm{LH} \%$ són ascendents, mentre que L\%, HL\%, !H\% i LHL\% són descendents). Aparentment, doncs, en català no hi hauria una prevalença d'accents tonals descendents, cosa que sí es troba en les llengües tonals i sembla que també en les entonatives, per bé que Gordon (2016: 261) adverteix que el coneixement tipològic sobre les llengües entonatives es troba encara més endarrerit que el que es té sobre les llengües tonals. Ara bé, també és cert que molt probablement els tons de caràcter ascendent, independentment de si són accents tonals o tons de frontera, són menys freqüents a nivell discursiu, però no hi ha estudis que hagin analitzat aquesta qüestió per al català. ${ }^{6}$ També cal destacar que aquesta prevalença pot canviar en varietats del català concretes com ara l'alguerès i el balear. Pel que fa al nombre d'accents tonals, el català es troba dins de la mitjana de les llengües romàniques (juntament amb el castellà, el portuguès $\mathrm{i}$ el romanès), ja que presenta 5 tipus d'accents tonals diferents, si no hi incloem determinats accents que són propis de varietats concretes. Altres llengües romàniques es trobarien per davall de la mitjana, com ara el francès, amb 4 accents tonals diferents, o per damunt, com ara l'italià, que presenta 7 accents tonals diferents (veg. Frota i Prieto 2015). ${ }^{7}$ En les llengües tonals, els sistemes més comuns són els de 2 o 3 tons (Maddieson, 1978; WALS, apud Gordon, 2016). Tanmateix, s'han documentat llengües que tenen fins a 7 tons lèxics. De les llengües tonals més parlades a Catalunya i les Illes Balears, l'igbo amb 4 tons i el xinès amb 4 o 6 tons depenent de la varietat, estarien per damunt de la mitjana. El bambara, en canvi, en presenta tan sols 2.

Al'hora de generar la melodia de la parla els diferents accents tonals es combinen amb els accents de frontera $\mathrm{i}$ formen diferents configuracions tonals. A la Taula 1, hi il·lustrem les configuracions nuclears, és a dir, el contorn terminal de cada enunciat, que trobem per al català (Prieto i Cabré, 2013; Prieto et al., 2015), així com els diferents significats que poden manifestar. Val la pena destacar que les interrogatives absolutes en català no necessàriament es produeixen amb un contorn ascendent. De fet, els contorns descendents són característics de l'alguerès, el català nord-occidental, part del català central i el mallorquí (Prieto i Cabré, 2013). Curiosament, però, les dades del WALS i Bolinger (1978) reflecteixen un biaix a favor de les cadències ascendents en les interrogatives absolutes (veg. Gordon 2016: 245246). En aquest sentit, doncs, la tendència del català a fer les interrogatives absolutes descendents representaria una tendència marcada, per bé que compartida amb altres llengües romàniques com ara el castellà central i del nordoest, el romanès de Transilvània i el sard (i, consegüentment, l'italià regional de Sardenya).

Les llengües també poden diferenciar-se per la densitat o escassetat d'esdeveniments tonals en el contorn. Segons Hellmuth (2007), això depèn de quin és el constituent prosòdic que actua com a domini per a la distribució dels accents tonals, és a dir, la paraula prosòdica, la frase accentual, la frase fonològica/intermèdia o la frase entonativa. El català, així com altres llengües romàniques com el castellà, el francès, l'italià i algunes varietats del portuguès europeu però també llengües d'altres famílies lingüístiques com l'àrab, presenta una distribució alta d'accents tonals. El domini per a la distribució dels accents tonals en català és la paraula prosòdica, a diferència del francès, en què s'assigna un accent tonal a cada frase accentual (Delais-Roussarie et al., 2015). El portuguès europeu estàndard, en canvi, es caracteritza per tenir una densitat baixa d'accents tonals. Aquesta diferència és fàcilment perceptible. Així doncs, les llengües amb alta densitat tonal són llengües que es perceben com a més "cantades" que les que tenen una densitat tonal més baixa. Val a dir que la densitat tonal d'una llengua també pot dependre del tipus d'oració. Així doncs, s'assumeix que en general les interrogatives tendeixen a presentar menys accents tonals que les declaratives. Consegüentment, llengües com el català, el castellà o algunes varietats del portuguès europeu es caracteritzen per presentar pocs accents tonals en les interrogatives. Tot i així, el portuguès brasiler, en canvi, té una alta densitat tonal independentment del tipus d'oració (veg. Frota i Prieto 2015). Que sapiguem, fins ara no s'ha proposat cap explicació per a aquesta diferència entre la modalitat declarativa i la interrogativa pel que fa la densitat tonal. Una possible causa (Feldhausen i Vanrell en procés de revisió) és que l'estructura informativa de les declaratives és diferent de la que trobem en les interrogatives. Així doncs, les declaratives es caracteritzen per constar d'un tema i un rema

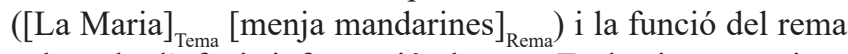
sol ser la d'afegir informació al tema. En les interrogatives absolutes, en canvi, el rema reflecteix la pressuposició que ha provocat que el parlant produís la interrogativa $i$ el tema sovint s'elideix o ocupa una posició perifèrica en l'oració. Així doncs, mentre que en les declaratives una densitat tonal més alta ajuda a distingir el tema del rema, en les interrogatives absolutes, l'ús d'un sol accent tonal sovint marca l'objecte pel qual s'està preguntant (per a més informació, veg. el treball de Feldhausen i Vanrell en procés de revisió).

Finalment, un altre aspecte que cal tenir en compte a l'hora de caracteritzar el català en relació amb altres llengües és el fraseig prosòdic, és a dir, la manera com segmentem l'enunciat en unitats prosòdiques inferiors. Per al català, i també per a altres llengües de la família romànica (castellà, italià, romanès), i la germànica (alemany, anglès i neerlandès), s'han descrit dos constituents per damunt de la paraula prosòdica: la frase entonativa FE (Intonational Phrase, IP) i la frase intermèdia fi (intermediate phrase, ip). Els dos nivells prosòdics es caracteritzen per un cert allargament abans de la pausa, que sol ser més important en el cas de la FE, i la presència de tons de frontera. El límit de la frase intermèdia té una importància cabdal a l'hora d'eliminar l'ambigüitat de frases com les que tenim a (1) o marcar dislocacions o anteposicions com les que apareixen a (2) i (3). En altres llengües com el portuguès, en canvi, només hi hauria evidència a favor d'un sol constituent prosòdic amb efectes entonatius, la frase entonativa, com veiem a (4) (Vigário 2003, Frota et al. 2015). En les llengües 


\section{Tipus de significat associat}

Declaratives (de focus ample, estret o contrastiu), interrogatives parcials

\section{Configuracions nuclears}

[La Maria menja mandarines] Focus ample La Maria menja [mandarines] Focus estret

Què li portaria?

$H^{\star} L \%$

$L^{\star} L \%$

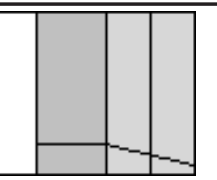

La Maria menja [mandarines] Focus contrastiu (i no pomes)

$L+H^{\star} L \%$
Interrogatives absolutes

(sovint encapçalades per la partícula que)
(Que) menges mandarines?

(i) $H+L^{*} L \%$
Interrogatives absolutes informatives (sense que inicial)
Menges mandarines?

\section{$\mathrm{L}^{\star} \mathrm{H} \%$}

Menges mandarines

(no sé si ho he sentit bé)?

\section{$\mathrm{L}+\mathrm{H}^{\star} \mathrm{H} \%$}

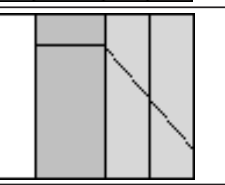

Interrogatives de tipus eco, reiteratives i d'incredulitat
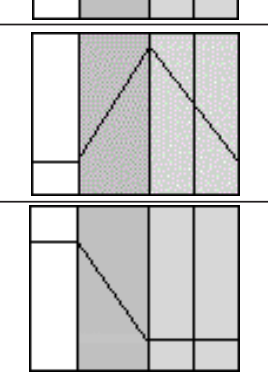

\section{$L+{ }_{i} H^{\star} L \%$}

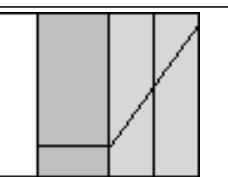

\section{Menges mandarines \\ Menges mandarines \\ (no m'ho puc creure)?}

(reintrodueixo aquesta informació al discurs)?

Maria!

$\mathrm{L}+\mathrm{H}^{*} \mathrm{HL} \%$

$L+H^{\star} L H \%$

Peticions, vocatius i altres oracions marcades

La Maria

(ja t'ho havia dit)!

$L+H^{*} L ! H \%$

$(\mathrm{Va}$,$) menja!$

$L^{*} H L \%$

(Va,) menja!

Taula 1. Principals configuracions nuclears documentades per al català, els significats que s'hi associen i exemples per a cada configuració ${ }^{8}$ 
esmentades, no es troben constituents que siguin superiors a la paraula prosòdica ni inferiors a la $\mathrm{FE} / \mathrm{fi}$ que siguin marcats entonativament. Ara bé, en llengües com el francès (també l'occità pel contacte amb el francès) (Delais-Roussarie et al., 2015) i el txec (Pešková acceptat), que tenen en comú el fet de ser llengües d'accent fix, la frase accentual és la unitat prosòdica rellevant per a l'accentuació (veg. l'exemple (5) per al francès). En francès, polonès i txec, per damunt de la frase accentual, hi ha també la frase intermèdia i la frase entonativa.

(1) a. ((La vella $\left.)_{\mathrm{fi}}(\text { llança l'amenaça })_{\mathrm{fi}}\right)_{\mathrm{FE}}$

b. ((La vella llança $\left.)_{\mathrm{fi}}(\text { l'amenaça })_{\mathrm{fi}}\right)_{\mathrm{FE}}$

(2) ((No l'he portat $)_{\mathrm{fi}}$, $\left.(\text { el cotxe })_{\mathrm{fi}}\right)_{\mathrm{FE}}$

(3) $\left((\mathrm{El} \text { cotxe })_{\mathrm{fi}}(\text { no he portat })_{\mathrm{fi}}\right)_{\mathrm{FE}}$

(4) (Ela bebe uma llimonada) $)_{\mathrm{FE}}$ 'Ella beu una llimonada'

(5) $\left.\quad\left((\text { Il réglait })_{\mathrm{fa}} \text { (le déchargement }\right)_{\mathrm{fa}}(\text { des casiers })_{\mathrm{fa}}\right)_{\mathrm{fi}}(($ sur les chariots $\left.\left.)_{\mathrm{fa}}(\text { des mareyeurs })_{\mathrm{fa}}\right)_{\mathrm{fi}}\right) \mathrm{FE}$

'Ell va encarregar-se de descarregar els prestatges en els carros dels majoristes de peix'

Com també hem vist en el cas del sistema vocàlic, pel que fa a l'entonació, el català tindria un grau de marcatge mitjà. Les estructures que en general es consideren més marcades són l'abundància d'accents tonals ascendents, sobretot en determinades varietats del català, i la presència d'interrogatives absolutes de caràcter descendent, que són també molt freqüents en varietats diatòpiques concretes.

\section{La intervenció didàctica}

L a Hipòtesi del marcatge diferencial té dues implicacions importants per a la didàctica del català com a llengua estrangera en relació amb l'ensenyament de les estructures de la LM en què existeix una relació de marcatge (Eckman 1977). La primera preveu que l'ordre d'adquisició natural, és a dir, sense cap tipus d'intervenció, seguirà l'ordre que vagi des de l'estructura menys marcada a la més marcada. La segona té a veure amb la direcció de la generalització de l'aprenentatge, que segons Eckman (1977), en canvi, anirà des de l'estructura més marcada a la menys marcada. A continuació explicarem quina aplicabilitat té cadascuna d'aquestes implicacions de la HMD.

La primera implicació, és a dir, l'ordre natural d'adquisició de determinades estructures, pot aplicar-se al disseny de programacions o materials didàctics en què es pretenguin introduir les diferents estructures en un ordre de complexitat creixent. Segons això, doncs, primer s'haurien d'introduir les estructures menys marcades i, per tant, amb un grau de dificultat menor, que les més marcades. Per tant, centrantnos en la pronúncia del català, primer caldria introduir les vocals mitjanes tancades /e, o/ i més endavant les vocals mitjanes obertes $/ \varepsilon, 0 /$; la vocal neutra, més marcada, s'hauria de presentar en posterioritat als altres segments vocàlics; i, en aquesta mateixa línia, caldria introduir primer les interrogatives de tipus ascendent que les interrogatives de tipus descendent. Pel que fa a la presentació de l'entonació d'altres tipus d'enunciats (declaratius, exclamatius, etc.) primer caldria donar prioritat als que fossin de caràcter descendent $i$, per tant, en general considerats menys marcats.

La segona implicació de la HDM té a veure amb la direcció de la generalització lingüística en l'aprenentatge de les estructures en què existeix una relació d'implicació. Concretament, l'estratègia de la HMD consistirà a intervenir en la interllengua de l'aprenent de manera que s'ensenyin aquelles estructures a partir de les quals l'aprenent pugui atènyer la màxima generalització. Dit d'una altra manera, a partir d'un conjunt d'estructures que tinguin una relació d'implicació, només s'ensenyarà l'estructura més marcada. La idea és que, una vegada que l'aprenent hagi adquirit l'estructura més marcada, totes les estructures menys marcades s'adquiriran de manera automàtica. La base d'aquesta intervenció didàctica és que l'estructura de la interllengua està determinada pels mateixos principis que governen l'adquisició de les primeres llengües. Segons això, doncs, caldria ensenyar explícitament als aprenents les vocals mitjanes obertes $/ \varepsilon, \mathrm{o} /$, la vocal neutra i el contorn descendent de les interrogatives, així com el seu context d'aparició. El fet d'aprendre aquestes estructures més marcades en el context que les requereix fa que l'aprenent pugui generalitzar l'equivalent no marcat en altres contextos. En el cas concret de les interrogatives absolutes, podríem dir que el fet de tenir interrogatives descendents és un tret tan excepcional en les llengües del món que, una vegada que l'aprenent hagi adquirit que les interrogatives encapçalades per la partícula que es produeixen amb un contorn descendent en català central, després serà capaç de produir la resta d'interrogatives absolutes de la llengua de manera ascendent automàticament. S'ha de tenir en compte, però, que la direcció de la generalització és sempre des de l'estructura més marcada a la menys marcada, no al contrari. Consegüentment, si un aprenent adquireix que a la grafia $<\mathrm{e}>$ hi correspon la pronúncia $[\mathrm{e}]$, no necessàriament serà capaç de pronunciar amb $[\varepsilon]$ mots en què aquesta vocal va seguida de la ròtica vibrant [r] com ara ferro, serra, gerro, etc.

Eckman (1977) no especifica si les implicacions que es deriven de la HMD són aplicables només a la dimensió perceptiva, a la de la producció o a les dues. Nosaltres, ben igual que el que es deriva dels treballs de Llach (2010) i Cicres i Llach (en procés de revisió), pensem que les implicacions són aplicables tant a la percepció com a la producció. Per exemple, Berent et al. (2007) (apud Cicres i Llach en procés de revisió) demostren que els trets o les estructures més marcats són els que provoquen més il·lusions perceptives que els no marcats. En conclusió, per tant, el tipus d'intervenció esperada seria el que parteix de la percepció de parells mínims o molt semblants entre les estructures més i menys marcades i després s'orienta cap al treball en producció de l'estructura més marcada, sempre 
fent explícit quin és el seu context d'aparició.

Finalment, cal destacar que, mentre que sí hi ha evidència a favor de les implicacions didàctiques de la HMD en l'adquisició de l'anglès com a llengua estrangera tant pel que fa a la fonologia com a la sintaxi (veg. Eckman 1977 per a una revisió), aquest és encara un camp a explorar en el cas concret de l'adquisició del català com a llengua estrangera. No obstant això, animem els docents i els investigadors a explorar l'adquisició dels aspectes descrits en aquest treball (el sistema vocàlic i l'entonació), però també d'altres com ara el sistema consonàntic, l'estructura sil·làbica o l'accent (Cicres i Llach en procés de revisió). Destaquem que la importància de la contribució que poden fer els universals lingüístics i la noció del marcatge tipològic a l'ensenyament del català rau en el fet que és una aplicació vàlida per als parlants de qualsevol de les llengües d'origen presents a Catalunya i a les Illes Balears. Si això ho extrapolem a l'àmbit específic del disseny i la creació de programacions i materials didàctics, veiem que possibilita uns materials molt més versàtils i sobretot més respectuosos amb la diversitat lingüística dels aprenents.

\section{Conclusions}

E $n$ aquest treball hem explorat la contribució que poden fer els universals lingüístics i la noció del marcatge tipològic a l'ensenyament i aprenentatge del vocalisme i l'entonació del català. Amb aquest propòsit, hem presentat les diferències que es deriven d'un enfocament contrastiu $i$ d'un enfocament basat en el marcatge tipològic, hem situat el vocalisme i el sistema entonatiu del català en relació amb les llengües dels nouvinguts més parlades a Catalunya $i$ a les Illes Balears i hem fet algunes consideracions sobre el tipus d'intervencions didàctiques que es deriven d'un enfocament basat en el marcatge tipològic. Com hem vist,

\section{${ }^{66}$ Destaquem que la} importància de la contribució que poden fer els universals lingüístics i la noció del marcatge tipològic a l'ensenyament del català rau en el fet que és una aplicació vàlida per als parlants de qualsevol de les llengües d'origen presents a Catalunya i a les Illes Balears. el sistema vocàlic i entonatiu del català presenta un grau de complexitat tipològica mitjà en relació amb llengües de famílies lingüístiques tan diverses com la família romànica, la germànica, l'eslava, la indoirànica, l'afroasiàtica, la nigerocongolesa, la sinotibetana, l'austronèsica i l'ameríndia. Aquesta complexitat tipològica es concreta en el contrast entre les vocals mitjanes tancades i obertes, la vocal neutra, la presència lleugerament majoritària de tons alts $i$ ascendents en la gramàtica entonativa del català i la d'interrogatives absolutes amb entonació descendent. Finalment, creiem que la HMD pot fer una contribució profitosa tant al disseny de programacions o materials didàctics com a la facilitació de l'ensenyament/aprenentatge de la pronúncia del català d'una manera més respectuosa amb la diversitat lingüística.

\section{Notes}

1 El terme marcatge es pot definir a partir de molts altres criteris (veg. Rice, 2007). Aquí hem pres una definició molt senzilla que té a veure amb el fet que l'estructura o el tret marcat sigui en general menys comú en les llengües del món.

2 Cal destacar que un dels trets definitoris de les vocals angleses és la durada vocàlica. Ara bé, s'ha de tenir en compte que les diferències de durada sempre s'acompanyen de diferències de qualitat. Com a exemple, la vocal [i:] és més llarga que la vocal [I], però al mateix temps més anterior $\mathrm{i}$ més tancada. Un altre aspecte a tenir en compte és que les vocals laxes de l'anglès ([I, $\mathrm{e}, \mathfrak{x , \Lambda}, \mathrm{p}, \mho])$, en posició tònica, només poden aparèixer en síl laba travada, és a dir, seguides de consonant. Com veiem en el text principal, això provocarà problemes a l'hora de pronunciar les vocals més properes a aquestes angleses en síl·laba oberta. Per a més informació sobre la caracterització del sistema vocàlic anglès i català, vegeu Cebrian (2019).

3 En les tasques de discriminació del tipus AXB, els participants senten tres estímuls seguits $\mathrm{i}$ han de dir si el d'enmig, l'estímul X, és més semblant a l'estímul que senten primer (A) o al que apareix en última posició (B).

4 Hem prioritzat el sistema vocàlic i el to i l'entonació per damunt del sistema consonàntic, l'accent o l'estructura sil-làbica per diverses raons: en primer lloc, alguns d'aquestes darrers aspectes, com hem vist, ja han estat tractats de manera aprofundida en treballs anteriors, també des d'una perspectiva tipològica (veg. Llach, 2010; i Cicres i Llach en procés de revisió); en segon lloc, hem considerat que tant el sistema vocàlic com el to i l'entonació il·lustraven clarament la contribució que poden fer el marcatge i la tipologia lingüística en l'ensenyament $\mathrm{i}$ aprenentatge de la llengua catalana com a llengua estrangera; finalment, que sapiguem, el to i, especialment, l'entonació encara no s'havien abordat des d'aquesta perspectiva en cap estudi. 
5 Tot i que la nasalitat en les vocals del català no és contrastiva, poden nasalitzar-se fonèticament sobretot quan van seguides d'una consonant nasal en posició de coda (Recasens, 2014: 172).

6 La freqüència interna a la llengua de determinats tons sí que és un tema estudiat en les llengües tonals. Remetem el lector a Gordon (2016: 224-227).

7 Val la pena dir que mentre que el català usa especialment l'entonació per marcar una gran varietat de significats semàntics i pragmàtics, altres llengües empren recursos diferents com ara partícules o marcadors discursius (veg. Prieto i Roseano, 2021).

8 Convidem el lector a visitar el web d'Aguilar et al. (coords.) (2009-2011) per escoltar exemples de les diferents configuracions nuclears.

\section{Bibliografia}

Aguilar, L., De-la-Mota, C., i Prieto, P. (Coords.) (20092011). Cat_ToBI Training Materials. http://prosodia.upf. edu/cat_tobi/

Barrios, S. (2018). Interlanguage Phonology. Dins J. Liontas (Ed.), Encyclopedia of English Language Teaching (2-7). John Wiley \& Sons, Inc.

Becker-Kristal, R. (2010). Acoustic typology of vowel inventories and DispersionTheory: insights from a large cross-linguistic corpus [Tesi doctoral no publicada]. UCLA.

Berent, I., Steriade, D., Lennertz, T. i Vaknin, V. (2007). What we know about what we have never heard: Evidence from perceptual illusions. Cognition, 104(3), 591-630.

https://doi.org/10.1016/j.cognition.2006.05.015

Best, C., i Tyler, M. (2007). Non-native and second language speech perception. Dins O. S. Bohn, M. J. Munro (Eds.), Language Experience in Second Language Speech Learning: In honor of James Emil Flege (15-34). John Benjamins.

https://doi.org/10.1075/lltt.17.07bes

Bolinger, D. (1978). Intonation across languages. Universals of Human Language 2 (471-524). Stanford University Press.

Carrera-Sabaté, J., i Prieto, P. (Coords.) (2012-2019). Guies de pronunciació del català. http://www.ub.edu/ guiesdepronunciacio

Cebrian, J. (2019). Percepció de vocals catalanes per part d'anglòfons: similitud interlingüística i conseqüències per a l'aprenentatge. Dins C. Pons-Moll, J. CarreraSabaté, J. Bach-Marqués, i L. Jiménez Tores (Eds.), Eines per a l'aprenentatge del catala com a L2/LE. Graó. https://doi.org/10.31009/resercle.2020.i1.17

Cicres, J. i Llach, S. (En procés de revisió). L'adquisició de la fonologia del català com a L2. Dins C. Pons, F. TorresTamarit, i M.M. Vanrell (Eds.), La fonologia del català. Editorial Tirant lo Blanch.

https://doi.org/10.2307/2846730

Clements, G.N. (2009). The role of features in speech sound inventories. Dins E. Raimy, i C. Cairns (Eds.), Contemporary Views on Architecture and Representations in Phonology (19-68). MIT Press.

https://doi.org/10.7551/mitpress/9780262182706.001.0001

Cutillas, A. (2014). Un món de sons. L’adquisició consonàntica del català en joves aprenents àrabs i xinesos. [Treball de Final de Grau no publicat.] Universitat Oberta de Catalunya.

d'Anglejan, A., i Tucker, G.R. (1975). The acquisition of complex English structures by adult learners. Language Learning, 25, 281-296.

https://doi.org/10.1111/j.1467-1770.1975.tb00247.x

Delais-Roussarie, E., Post, B., Avanzi, M., Buthke, C., Di Cristo, A., Feldhausen, I., Jun, S-A., Martin, P., Meisenburg, T., Rialland, A., Sichel-Bazin, R., i Yoon, H. (2015). Intonational phonology of French: Developing a ToBI System for French. Dins S. Frota, i Prieto, P. (Eds.), Intonation in Romance (63-100). Oxford University Press.

https://doi.org/10.1093/acprof:o so/9780199685332.003.0003

Dinnsen, D., i Eckman, F. (1978). Some substantive universals in atomic phonology. Lingua, 45, 1-14.

https://doi.org/10.1016/0024-3841(78)90017-7

Eckman, F. (1977). Markedness and the contrastive analysis hypothesis. Language Learning, 27, 315-330.

https://doi.org/10.1111/j.1467-1770.1977.tb00124.x

Eckman, F. (1985). Some theoretical and pedagogical implications of the markedness differential hypothesis. Studies in Second Language Acquisition, 7(3), 289-307. https://doi.org/10.1017/s0272263100005544

Eckman, F. (1991). The Structural Conformity Hypothesis and the acquisition of consonant clusters in the interlanguage of ESL learners. Studies in Second Language Acquisition 13, 23-41.

https://doi.org/10.1017/s0272263100009700 
Eckman, F. (2008). Typological markedness and second language phonology. Dins J.G. Hansen, i M.L. Zampini (Eds.), Phonology and Second Language Acquisition (95-115). John Benjamins Publishing Company.

https://doi.org/10.1075/sibil.36.06eck

Escudero , P., Hayes-Harb, R., Mitterer, H. (2008). Novel second-language words and asymmetrical lexical access. Journal of Phonetics, 36(2), 345-360.

https://doi.org/10.1016/j.wocn.2007.11.002

Feldhausen, I., Vanrell, M.M. (En procés de revisió). La interfície fonologia estructura-informativa. Dins C. Pons, F. Torres-Tamarit, i M. M. Vanrell (Eds.), La fonologia del català. Tirant lo Blanch.

Flege, J. E. (1995). Second language speech learning: Theory, findings and problems. Dins W. Strange (Ed.), Speech perception and Linguistic Experience: Theoretical and Methodological Issues (233-272). York Press.

Frota, S., i Prieto, P. (Eds.) (2015). Intonation in Romance. Oxford University Press.

Generalitat de Catalunya, Departament de Benestar i Família. (2000-2001, 2002-2003) Col·lecció “Llengua, immigració i ensenyament del català”. Agpograf.

Gordon, M. K. (2016). Phonological typology. Oxford University Press.

Gràcia Solé, L. (2004). Les llengües a Catalunya: diversitat tipològica. Dins L. Payrató, i F.X. Vila i Lluís (Eds.), Les llengües a Catalunya (147-173). Fundació Caixa de Sabadell.

Gràcia Solé, L. (2005). Lingüística contrastiva. Articles de Didàctica de la Llengua i de la Literatura 38, 15-26.

Gradman, H. (1971). Limitations of contrastive analysis predictions. Working Papers in Linguistics, 3, 11-15.

Hamann, S., i Torres-Tamarit, F. (2018). Stressed schwa takes over in Eivissan Catalan. Pòster presentat a LabPhon16 - Variation, development and impairment: between phonetics and phonology, Faculdade de Letras, Universidade de Lisboa, Portugal, 19-22 de juny, 2018.

Hellmuth, S. (2007). The relationship between prosodic structure and pitch accent distribution: evidence from Egyptian Arabic. Linguistic Review, 24, 291-316. https://doi.org/10.1515/tr.2007.011

Julià, J. (2014). Catalan. Dins C. Fäcke (Ed.), Manual of Language Acquisition (345-370). Mouton de Gruyter.
Kuhl, P. K., i Iverson, P. (1995). Linguistic experience and the perceptual magnet effect. Dins W. Strange (Ed.), Speech perception and Linguistic Experience: Theoretical and methodological Issues (121-154). York Press.

Lado, R. (1957). Linguistics across cultures. University of Michigan Press.

Llach, S. (2010). Aprendre els sons del català en un entorn multilingüe: una proposta. Articles de Didàctica de la Llengua i de la Literatura, 51, 79-97.

Maddieson, I. (1992). UCLA Phonological Segment Inventory Database. University of California Los Angeles, Los Angeles.

Maddieson, I. (2013). Tone. Dins M. S. Dryer, i M. Haspelmath (Eds.), The World Atlas of Language Structures Online. Max Planck Institute for Evolutionary Anthropology.

Mora, J. C., i Nadeu, M. (2012). L2 effects on the perception and production of a native vowel contrast in early bilinguals. International Journal of Bilingualism, 16, 484-499.

https://doi.org/10.1177/1367006911429518

Moulton, W. G. (1962). The Sounds of English and German. University of Chicago Express.

Pešková, A. (Acceptat). The Intonational Phonology of Czech. Dins S. A. Jun (Ed.), Prosodic Typology III: The Phonology of Intonation and Phrasing. Oxford University Press.

https://doi.org/10.1017/s0952675715000202

Prieto, P., Borràs-Comes, J., Cabré, T., Crespo-Sendra, V., Mascaró, I., Roseano, P., Sichel-Bazin, R., i Vanrell, M.M. (2015). Intonational phonology of Catalan and its dialectal varieties. Dins S. Frota, i P. Prieto (Eds.), Intonation in Romance (9-62). Oxford University Press. https://doi.org/10.1093/acprof:o so/9780199685332.003.0002

Prieto, P., i Cabré, T. (Eds.) (2013). L'entonació dels dialectes catalans. Publicacions de l'Abadia de Montserrat.

Prieto, P., Roseano, P. (2021). The encoding of epistemic operations in two Romance languages: The interplay between intonation and discourse markers. Journal of Pragmatics, 172, 146-163.

https://doi.org/10.1016/j.pragma.2020.11.008

Recasens, D. (2014). Fonètica i fonologia experimentals del català. Vocals i consonants. Institut d'Estudis Catalans.

Rice, K. (2007). Markedness in phonology. Dins P. de Lacy 
(Ed.), The Cambridge Handbook of Phonology (79-98). Cambridge University Press.

https://doi.org/10.1017/cbo9780511486371.005

Richards, J. (1971). A non-contrastive approach to error analysis. English Language Teaching, 25, 204-219.

Roseano, P. 2019. Prosòdia de l'italià i prosòdia del català: Pautes per a una didàctica contrastiva. Dins C. PonsMoll, J. Carrera-Sabaté, J. Bach-Marquès, i L. Jiménez Torres (Eds.), Eines per a l'aprenentatge del català com a L2 i LE (81-94). Graó.

https://doi.org/10.31009/resercle.2020.i1.17

Selinker, L. (1972). Interlanguage. International Review of Applied LInguistics, 10, 209-231.

Showalter, C.E., Hayes-Harb, R. (2013). Unfamiliar orthographic information and second language word learning: A novel lexicon study. Second Language Research, 29(2), 185-200.

https://doi.org/10.1177/0267658313480154

Torres, M. (1983). Aspectes del vocalisme tònic eivissenc. Eivissa, 14, 22-23.

Vigário, M. (2003). Prosody and sentence disambiguation in European Portuguese. Catalan Journal of Linguistics, 2, 249-78.

https://doi.org/10.5565/rev/catjl.52

Veny, J. (1977). Aproximació a l'estudi del dialecte eivissenc. Randa, 5, 5-42.

Villangómez, M. (1978). Curs d'iniciació a la llengua: normes gramaticals, lectures eivissenques $i$ formentereres. Institut d'Estudis Eivissencs.

Wang, L. (2019). Estudi contrastiu de l'estructura sil-làbica del català $i$ del xinès estàndards $i$ de les implicacions segmentals més rellevants per als aprenents sinòfons. [Tesi doctoral no publicada.] Universitat de Barcelona.

https://doi.org/10.31009/resercle.2020.i1.04

Wang, L. (2020). La producció dels sons oclusius del català per part dels aprenents sinòfons: estudi contrastiu, anàlisi d'errors i proposta de millora. Resercle, 1, 42-65.

https://doi.org/10.31009/resercle.2020.i1.04

Zhou, Ch., i Hamann, S. (2020). Cross-linguistic interaction between phonological categorization and orthography predicts prosodic effects in the acquisition of Portuguese liquids by L1-Mandarin learners. Proceedings of Interspeech 2020, Hong Kong, 4486-4490.

https://doi.org/10.21437/interspeech.2020-2689 